\section{Is the regulation of Z-drugs in Brazil in line with scientific research and international standards?}

Rev Bras Psiquiatr. 2018;40:112

Brazilian Journal of Psychiatry

doi:10.1590/1516-4446-2017-2372

Z-drugs (i.e., zopiclone, zaleplon and zolpidem) first appeared on the market as a substitute for benzodiazepines (BZDs), purportedly having a lower risk of addiction due to improved pharmacokinetics. However, recent research has shown they may be similar to BZDs in terms of cognitive, behavioral and psychomotor performance ${ }^{1}$; risk of dependence ${ }^{2}$; and mortality. ${ }^{3}$ Nevertheless, this scientific knowledge has not seemed to influence the rate of Zolpidem consumption, especially in developing countries, ${ }^{4}$ where regulatory measures may be more vulnerable to the influence of the pharmaceutical industry. In light of this research, the Food and Drug Administration (FDA) released two Drug Safety Communications (DSCs) in 2013 regarding products containing Zolpidem, describing the risk of next-day impairment and recommending lower starting doses, particularly for women. ${ }^{5}$

Following this FDA action, a number of studies reported reductions in the prescribed dose, ${ }^{6}$ reducing the risks of adverse effects. However, other research has shown that more than $70 \%$ of general practitioners do not recognize or even evaluate the side effects of these hypnotics, ${ }^{7}$ and that the beliefs of clinicians and patients about the drugs' safety do not seem to keep pace with advances in research, producing a gap between scientific evidence and clinical practice. Education, backed by legislation, about the effects of the chronic use of these medications is extremely important to ensure appropriate prescription and reduce misuse. In Brazil, the regulations for prescribing Z-drugs are weak: The risk of dependence is explicitly stated on the leaflet accompanying Zolpidem although it is not classified under the same regulations as BZDs. A standard prescription is used rather than the specific blue one required for BZDs, and their packaging presents neither the customary black stripe found on the most strictly controlled medications nor the words "the abuse of this medicine can cause dependence," as can be found on BZDs. The packaging features only a red stripe, typical of medications such as antiepileptics or antidepressants, which may lead consumers to believe the medicine has a different status than BZDs and carries little or no dependence risk or other negative effects.

This lack of control and medical guidance could potentially contribute to dependence problems or other consequences. Although there is still a lack of evidence about the effect size for outcomes such as dementia, infections or cancer, as well as the heterogeneity of risk among different Z-drugs, there is mounting evidence that Z-drugs are similar to BZDs, at least with respect to motor vehicle accidents, falls and fractures. ${ }^{8}$
Therefore, it is urgently necessary to disseminate information about the similarities between BZDs and Z-drugs, since they have been shown to cause similar adverse effects and dose escalation ${ }^{1}$ due to tolerance, and thereby challenge the belief among professionals and patients that Z-drugs present less risk. ${ }^{7}$ In addition, further research into the influence of regulation on the consumption of hypnotics is required. Policy makers must be made more aware of Z-drugs' potential for dependence and be encouraged to adopt measures such as those of the FDA, bringing regulations in line with those of BZDs in order to increase patient and physician knowledge about this issue and reduce potential harm.

Víviam Vargas de Barros, Emérita S. Opaleye, Ana R. Noto

Núcleo de Pesquisa em Saúde e Uso de Substâncias (NEPSIS), Departamento de Psicobiologia, Universidade Federal de São Paulo (UNIFESP), São Paulo, SP, Brazil.

Submitted Jun 15 2017, accepted Nov 062017.

\section{Acknowledgements}

We would like to thank the Conselho Nacional de Desenvolvimento Científico e Tecnológico (grant 407116/ 2013-3) and Fundação de Amparo à Pesquisa do Estado de São Paulo (process 2013/20367-6) for financial support, and the Associação Fundo de Incentivo à Pesquisa (AFIP) for support with resources.

\section{Disclosure}

The authors report no conflicts of interest.

\section{References}

1 Gunja N. In the Zzz zone: the effects of Z-drugs on human performance and driving. J Med Toxicol. 2013;9:163-71.

2 Yen CF, Yen CN, Ko CH, Hwang TJ, Chen CS, Chen TT, et al. Correlates of dependence and beliefs about the use of hypnotics among zolpidem and zopiclone users. Subst Use Misuse. 2015;50: 350-7.

3 Weich S, Pearce HL, Croft P, Singh S, Crome I, Bashford J, et al. Effect of anxiolytic and hypnotic drug prescriptions on mortality hazards: retrospective cohort study. BMJ. 2014 Mar 19;348:g1996. doi: 10.1136/bmj.g1996.

4 Alessi-Severini S, Bolton JM, Enns MW, Dahl M, Collins DM, Chateau D, et al. Use of benzodiazepines and related drugs in Manitoba: a population-based study. CMAJ Open. 2014;2:E208-16.

5 US Food and Drug Administration (FDA). FDA Drug Safety Communication: FDA approves new label changes and dosing for zolpidem products and a recommendation to avoid driving the day after using Ambien CR. 2013 Oct 1 [cited 2017 Nov 21]. www.fda.gov/ drugs/drugsafety/ucm352085.htm.

6 Norman JL, Fixen DR, Saseen JJ, Saba LM, Linnebur SA. Zolpidem prescribing practices before and after Food and Drug Administration required product labeling changes. SAGE Open Med. 2017 May 5;5:2050312117707687. doi: 10.1177/2050312117707687. eCollection 2017.

7 Hoffmann F. Benefits and risks of benzodiazepines and Z-drugs: comparison of perceptions of GPs and community pharmacists in Germany. Ger Med Sci. 2013 Jul 18;11. doi: 10.3205/000178. Print 2013.

8 Brandt J, Leong C. Benzodiazepines and Z-drugs: an updated review of major adverse outcomes reported on in epidemiologic research. Drugs R D. 2017;17:493-507. 